\title{
THE UNABOMBER'S ETHICS
}

Penultimate version. Published in Bioethics 33 (2) 2019: 223-229. https://doi.org/10.1111/bioe.12494

\begin{abstract}
In this paper I present and criticize Ted Kaczynski's ('The Unabomber') theory that industrialization has been terrible for humanity, and that we should use any means necessary, including violent means, to induce a return to pre-industrial ways of living. Although Kaczynski's manifesto, 'Industrial Society and its Future,' has become widely known, his ideas have never before been subject to careful philosophical criticism. In this paper I show how Kaczynski's arguments rely on a number of highly implausible philosophical premises. I further make the case that although his theory as a whole should be rejected, Kaczynski raises a number of worries about technological development that ought to receive serious attention. Some of these worries have recently come to be shared by prominent defenders of human enhancement, including Nick Bostrom and Julian Savulescu. In the last section I indicate why I believe it is important that academic philosophers scrutinize ideas that motivate acts of violence.
\end{abstract}

\section{INTRODUCTION}

Between 1978 and 1995, Ted Kaczynski killed three and wounded 23 by sending mail bombs to a number of scientists and leaders in the technology industries. Kaczynski was an assistant professor of mathematics at Berkeley who came to despise industrial civilization, resigned from his academic position, and moved to live alone in a cabin in the woods of Montana. Before he was identified, the FBI referred to the person behind the mail bombs as the 'Unabomber,' an abbreviation of 'University and Airline Bomber,' a name by which Kaczynski later came to be widely known. In 1995, Kaczynski, using the pen name 'FC,' sent a 35,000-word manifesto titled 'Industrial Society and Its Future' to The New York Times and The Washington Post with the threat that he would intensify the killings unless the manifesto was printed. [1] The FBI recommended that the newspapers print the manifesto in the hope that this would help them identify the culprit. After the manifesto (often referred to as the 'Unabomber Manifesto') was printed, it was read by members of Kaczynski's family who recognized his style of argument and contacted the police. This led to his arrest.

Kaczynski is still alive and has now spent 22 years in a high-security prison. During this time he has written a monograph, Anti-Tech Revolution: Why and How, which was published in August 2016. [2] In this work he provides a more elaborate defense of his view.

My first aim in this paper is to reconstruct Kaczynski's core arguments in 'Industrial Society and its Future' (1995) and Anti-Tech Revolution (2016). ${ }^{[3]}$ I then show how his arguments rely on a number of highly implausible ethical premises that have hitherto not been made explicit and criticized. Thereafter I examine where Kaczynski's arguments lead given more reasonable ethical premises.

There are obvious downsides to discussing ideas that are spread by means of violence. We do not, after all, want to contribute to making violence an effective means to get ideas across. I think, however, that the present discussion is justified. One reason is that Kaczynski's views are already widely known. Recently, the television series Manhunt: Unabomber has received significant attention. ${ }^{[4]}$ Although it would perhaps have been best if they were not widely known, the worst situation is one in which they are widely known, yet are never subject to careful criticism. I hope that by making his philosophical shortcomings explicit, I can help demystify Kaczynski and perhaps help dissuade some of those who would otherwise be attracted to his views. I shall return to this point in the conclusion.

Hitherto, the only academic philosopher who has discussed Kaczynski's ideas in any detail is David Skrbina. Skrbina, however, is very sympathetic to Kaczynski, has exchanged letters with him over many years, has published articles in a volume together with him, and calls him 'a revolutionary for our time.' It should be emphasized that Skrbina does not endorse Kaczynski's calls for violence.[5]

Another reason for discussing Kaczynski's ideas is that they are, by their own merits, worthy of discussion. It would be a mistake to assume that ideas must be intellectually worthless simply 
because they motivate acts of violence. James Q. Wilson, a prominent political scientist, wrote in the The New York Times in 1998 that Kaczynski's manifesto is 'a carefully reasoned, artfully written paper... If it is the work of a madman, then the writings of many political philosophers - Jean Jacques Rousseau, Tom Paine, Karl Marx - are scarcely more sane.'[6] For reasons that will become clear, I think Wilson's praise is exaggerated. Nevertheless, Kaczynski raises a number of worries that ought to be considered. It is noteworthy that some of these worries have recently been raised by defenders of human enhancement (or transhumanism), most prominently Nick Bostrom and Julian Savulescu.

\section{KACZYNSKI'S ARGUMENT}

One of Ted Kaczynski's central claims in 'Industrial Society and Its Future' (1995) is that technology makes us live under conditions 'radically different from those under which the human race evolved.' We live in densely populated areas, in isolation from wild nature, and we suffer the consequences of rapid societal changes have broken down the tightly knit communities in which we evolved to thrive. ${ }^{77}$ Technology, he argues, has also taken away our ability to control our lives:

Primitive man, threatened by a fierce animal or by hunger, can fight in self-defense or travel in search of food ... The modern individual on the other hand is threatened by many things against which he is helpless: nuclear accidents, carcinogens in food, environmental pollution, wars, increasing taxes, invasion of his privacy, large organizations, nationwide social or economic phenomena that may disrupt his way of life. [8]

Moreover, while in previous centuries we thrived by using our mental and physical efforts to sustain ourselves, technology has made our lives monotonous and dull.[9]

In Kaczynski's view, we nevertheless need to feel that we do something meaningful, that we are in control, and that we sustain ourselves through our actions. For this reason, he explains, we engage in 'surrogate activities.' Surrogate activities are activities that aim, not at satisfying real needs, but at giving us 'fulfillment.' Kaczynski suggests that the pursuit of wealth (beyond the minimum required to live) is a typical example of a surrogate activity. We do not really need excess wealth, but we tell ourselves that we do and thus create a goal that we can strive to achieve. Scientific research, he thinks, is also largely a surrogate activity:

With possible rare exceptions, their [scientists'] motive is neither curiosity nor a desire to benefit humanity but the need to go through the power process: to have a goal (a scientific problem to solve), to make an effort (research) and to attain the goal (solution of the problem.) Science is a surrogate activity because scientists work mainly for the fulfillment they get out of the work itself. ${ }^{[10]}$

Kaczynski argues that actions that aim at fulfillment, rather than at the satisfaction of real needs, will never be truly fulfilling. Only real struggle gives real fulfillment. In being denied real struggle, and made to submit to large social structures, modern humans suffer.

Technology is virtually unstoppable. New technologies provide convenient solutions to pressing problems, and for that reason, it always seems prudent to embrace them, even if the long-term consequences might be dire. Cars, while they were very useful at first, are noisy and polluting, Kaczynski explains, and have resulted in cities developing in ways that make it difficult to be a pedestrian, thus prompting even more people to buy and use cars. ${ }^{[11]}$ The same principle is at work in the development of biotechnology:

Few people will resist the introduction of a genetic technique that eliminates hereditary disease. It does no apparent harm and prevents such suffering. Yet a large number of genetic improvements taken together will make the human being into an engineered product rather than a free creation of chance. [12]

Kaczynski thinks technological progress is out of control. Soon, he speculates, we will have intelligent machines, the result of which will either be that humans are eradicated or, if we are not, that we will all (perhaps with the exception of a small elite) live like domesticated animals in a society resembling the one described by Aldous Huxley in Brave New World:

They will see to it everyone's physical needs are satisfied, that all children are raised under psychologically hygienic conditions, that everyone has a wholesome hobby to keep him busy, and that 
anyone who may become dissatisfied undergoes 'treatment' to cure his 'problem.' Of course, life will be so purposeless that people will have to be biologically or psychologically engineered either to remove their need for the power process or to make them 'sublimate' their drive for power into some harmless hobby. These engineered human beings may be happy in such a society, but they most certainly will not be free. They will have been reduced to the status of domestic animals. ${ }^{[13]}$

The only way to avoid eradication or Brave New World, Kaczynski suggests, is to bring human societies back to their pre-industrial state. We should return to live 'close to nature' and accept nothing more advanced than 'small-scale technology' which 'can be used by small-scale communities without outside assistance,' such as water wheels and the works of blacksmiths. ${ }^{[14]}$ Kaczynski argues that in order to reach this goal 'factories should be destroyed, technical books burned, etc.' He acknowledges that a large-scale fight against technology will cause significant suffering, but in his view suffering and even death are preferable to 'liv[ing] a long but empty and purposeless life.'[15]

Kaczynski wants to initiate a social movement that will bring down industrial civilization. How should the movement go about doing that? Although Kaczynski provides very little guidance in 'Industrial Society and Its Future,' he discusses the practical implications of his views in greater length in The Anti-Tech Revolution. Before he outlines his recommendations, however, he starts the book by providing an account of how he understands social change and the difficulties of predicting the development of complex social systems. He argues, by appeal to butterfly effects, that 'no society can accurately predict its own behavior over any considerable span of time.' Since control requires prediction, Kaczynski argues that '[s]ocieties can never be subject to rational human control.'[16]

Kaczynski also provides additional reasons for believing that technological development is extremely hard to stop. One reason, which relies on his understanding of complex systems, is that the individuals or groups that restrain their use of technology will tend to be disadvantaged compared to those who don't. Technological development is an arms-race in which moderates are weeded out. He explains, for instance, that those who use fossil fuels will tend to thrive more than those who restrict themselves to using renewable sources of energy. Indeed, those who use only renewables leave more fossil fuels to their competitors. For this reason he concludes that the environmental movement will never succeed in counteracting the harmful effects of technology.[17]

Rather than pursuing reform and moderation, Kaczynski seeks to initiate a revolutionary movement that will aim to 'kill' technological civilization. This is a good aim for a revolutionary movement, he argues, since it is a simple aim that has a clear criterion for success, and once success is achieved, the revolution will be irreversible. These features, he suggests, will make the anti-tech revolution more likely to succeed than the 20th Century Socialist revolutions. The Socialist revolutionaries had a complicated goal and a vague success criterion. Eradicating technology is more clear-cut. Moreover, since the Socialist revolutions only changed the structure of society, the revolutions could be undone. The anti-tech revolution, by contrast, essentially involves the destruction of all advanced technological tools.

How can the anti-tech revolution be achieved? Kaczynski recommends the formation of a small and committed group that will work to erode respect for technology, and that should see future failures and crises as windows of opportunity. During crises, Kaczynski writes, 'desperation and anger will soon degenerate into despair and apathy - unless the revolutionaries are able to step in at that point and inspire them with a sense of purpose, organize them, and channel their fear, desperation, and anger into practical action.' ${ }^{[18]}$ The members of the movement, however, should not just convince people through debate and political action: They should be prepared to die. To find inspiration, Kaczynski suggests that '[w]e need only think of the early Christian martyrs, of $\mathrm{Al}$ Qaeda, the Taliban, the Islamic suicide bombers, or of the assassins of the Russian Revolution.' [199] Through the efforts of the revolutionaries, 'the existing power-structure will be in disarray, disoriented, and riven by internal conflict,' and then the revolutionaries can take charge, like revolutionaries once did in Russia and Cuba. ${ }^{[20]}$ Kaczynski thinks that 'when revolutionaries have brought the technological system to an abrupt halt in the United States, the economy of the entire world will be severely disrupted and the acute crisis that results will give the anti-tech revolutionaries of all nations the opportunity that they need.' The anti-tech revolutionaries must then have no 'scruples,' proceed 'no matter what,' and be afraid of nothing, not even nuclear war. ${ }^{[21]}$ The idea is that, through a coordinated effort, a committed minority will bring down technological 
civilization and allow humanity to start from scratch in small-scale communities in their natural surroundings. There is, Kaczynski thinks, no other way to stop the rapid growth of technology, and unless we stop it, humanity as we know it will either be wiped out or we will end up in a society resembling that envisioned in Brave New World.

\section{THE PROBLEMS WITH KACZYNSKI'S ARGUMENT}

Kaczynski's views are radical and dangerous. Nevertheless, it is difficult to deny that some of his concerns are reasonable. Over a short time-span, technology and industrialization have indeed brought about radical changes, many of which are negative. There is, moreover, little reason to believe that technological progress is slowing down, and admittedly, we know very little about the long-term consequences of the technological innovations that we make use of today.

So what are the problems with Kaczynski's argument? One striking problem is that in assessing the effects of technology on human life, Kaczynski considers only the negative effects. This makes him leave out from his inquiry a number of very important facts, such as the fact that prior to the industrial revolution, all countries in the world had a living standard comparable to today's standard in Africa south of Sahara, and that since the late 18th Century, the global average life expectancy at birth has more than doubled. ${ }^{222}$ It is hard to deny that these are real improvements and that they were made possible by technologies, perhaps most centrally artificial fertilizers, agricultural machinery, water chlorination, sewer systems, antibiotics, and vaccines. It is also hard to deny that a wide range of other technologies_reading glasses, painkillers, printing presses, light bulbs, pianos, music recordings, trains-have enriched the lives of billions. ${ }^{[23]}$

Why doesn't Kaczynski include these benefits in his assessment of technology? One reason might be that he thinks the benefits are widely known, and that his specific job is to list the harms. I think, however, that another reason should be also considered, namely that Kaczynski assumes an ethical theory according to which the benefits of technology have little or no real value.

When one reads 'Industrial Society and its Future' and Anti-Tech Revolution, it is hard not to notice that Kaczynski evaluates problems caused by technology very differently than how he evaluates problems that arise in technology's absence. This is most apparent in the middle paragraphs of 'Industrial Society and its Future,' in which Kaczynski compares industrial and pre-industrial life. After he has given an elaborate account of human powerlessness in industrial societies, he makes a concession: 'It is true that primitive man is powerless against some of the things that threaten him; disease for example.'[24] Kaczynski does not, however, seem to think that this is a very significant problem. Instead he writes: 'But he can accept the risk of disease stoically.' This response invites a follow-up question: If the badness of the problems faced by 'primitive man' can be avoided if one accepts them stoically, then why can't the badness of the problems faced by people in industrialized societies also be avoided through stoicism? The only explanation given by Kaczynski is that whereas a problem caused in the absence of technology 'is part of the nature of things, it is no one's fault,' a problem caused by technology is 'imposed.' [25] Of course, it makes sense to hold that while no-one is responsible for what nature does, someone might be responsible for what humans do. Kaczynski, however, does not seem to be concerned with assigning responsibility or blame; he is concerned with comparing the quality of human life in industrial versus pre-industrial societies. It seems, therefore, that Kaczynski holds that while a problem caused by technology is very bad indeed, a problem caused by nature, though it can be frustrating, is not nearly as bad, at least not in an ethically relevant way. It appears that on Kaczynski's view, two equally hopeless situations can differ dramatically in how bad they are depending on whether the situation is caused by technology or caused by things in nature that count as non-technological.

This evaluative asymmetry can help explain several of Kaczynski's priorities and areas of focus. It can explain why he is worried that our lives now depend on the operation of power plants that might fail, but not worried that pre-industrial lives depended on rain showers that might fail to come as expected; worried that people today are oppressed by bureaucracies, but not worried that people were previously oppressed by their tribes; worried that people now do tedious office work but not worried that work in pre-industrial societies could also be tedious. The picture that emerges is that in Kaczynski's view, the harms that are averted by technology were not ethically relevant harms to 
begin, and that what we gain from technology today does not count as ethically relevant benefits. Given this picture, it makes sense why Kaczynski counts only the downsides of technology: There are few or no ethically relevant upsides to count.

In addition to holding that the problems caused by technology are bad and that the problems that arise in the absence of technology are not bad, Kaczynski also seems to hold that the very existence of technology taints and devalues the parts of the world that remain unaffected by technology. In discussing the coercive nature of industrial society he makes another interesting concession, namely that although industrial societies are coercive, people are free to leave these societies if they wish: 'Legally there is nothing to prevent us from going to live in the wild like primitive people.'[26] At first glance, one might expect that, even on Kaczynski's view, this should count in industrial society's favor. Kaczynski himself made use of the option to leave when he resigned from his academic position and withdrew to live in the woods. He remains unimpressed, however, and writes that having this option does not count as a real benefit since

the value of the opportunity [to move into the wild] is destroyed by the very fact that society gives it to them. What [people] need is to find or make their own opportunities. As long as the system GIVES them their opportunities it still has them on a leash. To attain autonomy they must get off the leash. ${ }^{227}$

On Kaczynski's terms, therefore, industrial society simply cannot win: All that it touches, and indeed all that it refrains from touching, is contaminated.

These evaluative standards are not incidental to Kaczynski's argument. He crucially relies on these standards to get from his empirical observations to his normative conclusions. He does not, however, make the standards explicit and he never produces arguments to support them. When one first reads 'Industrial Society and its Future' and Anti-Tech Revolution, one is struck by how empirically oriented the works are. Although this might perhaps be viewed as a strength, it serves to hide the fact that Kaczynski reaches his conclusions by appeal to ethical principles that rig the game strongly in the disfavor of technology.

In order to understand Kaczynski's world-view, it would have been useful to know what specific normative theory he assumes. Judging from his written work, he might be read as a perfectionist, as someone who believes in the ultimate value of naturalness, or as someone who believes in the ultimate value of struggle or freedom. He might perhaps also be read as believing in the ultimate value of fulfillment, and to hold that struggle and freedom are valuable as means towards fulfillment, or to hold a pluralist theory. Sadly, however, he is never explicit about his ethical standards. Neither is he explicit about why the things that he takes to be valuable are threatened by, yet cannot be enhanced by, technology.

Let us now say that we reject Kaczynski's sharp asymmetry between how the problems caused by technology and the problems that arise in the absence of technology should be assessed. Does this give us reason to reject his argument as a whole, or might some aspects of his theory survive even if we employ standards of evaluation that count the harms and benefits of technology and non-technology more evenhandedly? Although, as I shall argue, most of Kaczynski's practical suggestions would need to be changed, some of his points remain forceful.

Technology clearly is a powerful force that develops rapidly, and today's technological developments are bound to have effects-including negative effects-beyond what we are presently able to predict. No-one knew, or could have known, beforehand that the printing press would trigger the Reformation, that the industrial revolution would trigger the rise of Communism, or that the splitting of the atom would trigger the invention of the atomic bomb. In this sense, technological progress is, and has always been, out of control, since as Kaczynski rightly points out, control presupposes prediction. Even if we could predict the effects of technology more accurately, however, it would still not be clear that we would have the power to control its development. Technological progress is indeed an arms-race in which individuals and groups face incentives to develop and use technologies before they can be properly regulated. If one group does not develop and use a technology, other groups will, and that will give them an advantage. We therefore face both an epistemic problem and a coordination problem when we seek to control technological progress. 
Interestingly, worries similar to these have come to be raised by theorists that are commonly taken to be at the opposite side of Kaczynski in the debate about the ethics of emerging technologies. One early example is the computer scientist Bill Joy who, in 'Why the Future Doesn't Need Us' (2000), voices concerns about the risks posed by genetic engineering and nanotechnology. ${ }^{[28]}$ Such technologies, Joy argues, are tools that we cannot yet know how will be used, which is worrisome given that, arguably, they have the potential to eradicate humanity. More recently, Nick Bostrom, a prominent defender of human enhancement and transhumanism, has argued that the development of artificial intelligence exposes humanity to a significant risk of eradication. [29] Like Kaczynski, Bostrom is concerned that as a result of a technological arms race, more powerful forms of artificial intelligence will be developed and put to use, including in the development of autonomous weapons, before we know how to handle them. Another leading defender of enhancement, Julian Savulescu, frames his worry in a way that seem even more in line with Kaczynski's view, namely that human nature is incompatible with rapid technological progress. In Unfit for the Future (2012), co-authored with Ingmar Persson, Savulescu argues that technology increasingly gives us powers far beyond what our evolved moral psychologies are equipped to handle. Human shortsightedness, aggression, and xenophobia, although they were adaptive when we lived in small tribes on the African savannah and the most powerful weapons at our disposal were spears and clubs, can lead to catastrophic consequences in a technologically advanced society. .30$]$ We are, Savulescu thinks, unfit for the future. Kaczynski's view, we might say, is that the future is unfit for us.

Although it is noteworthy that Kaczynski, Bostrom, and Savulescu share a number of worries, they diverge strongly both in their views on what futures are possible and in their views on what actions we should take. In the case of possible futures, Bostrom and Savulescu believe that technology can also bring about a very good future: a future in which we live longer, richer, and more enjoyable lives, and are better shielded from violence, suffering, and disease than we are today. ${ }^{[31]}$ Kaczynski, on the other hand, thinks that the range of possible futures is very limited: unless we return to preindustrial life, he thinks, there are only two available outcomes: eradication and Brave New World. Although it could perhaps be argued that these are the two most likely outcomes, he provides no arguments that support this, and his prediction seems to sit uncomfortably with his broader views on social change and his conviction that ' $[\mathrm{n}] \mathrm{o}$ society can accurately predict its own behavior over any considerable span of time.'[32]

Regarding what steps humanity should take, Bostrom's and Savulescu's suggestions are that we should invest heavily in research on existential risk, seek to build stronger institutions, and facilitate stronger international cooperation in order to enable more effective regulation of new technologies. ${ }^{[33]}$ In addition, Savulescu defends increased surveillance and 'moral enhancement,' the use of social and (if feasible) biological means to make us more cooperative, impartial, rational, and empathetic. ${ }^{[34]}$ Interestingly, Kaczynski touches on a suggestion bordering on moral enhancement in the manifesto when he argues that eradication is a likely outcome for humans 'unless they were biologically or psychologically engineered to adapt to such a way of life.'[35] In Kaczynski's view, however, interventions like these are off the table, presumably not because he believes that they are technologically impossible (in that case he would not need to be worried about them), but because he believes that a life altered by technology would, almost by definition, not be a good life.

It is difficult to estimate the extent to which Bostrom's and Savulescu's suggestions provide feasible ways to secure a good future. The feasibility of Kaczynski's suggestion is easier to estimate. On the one hand, Kaczynski does nothing to hide the brutality of his proposals. He is ready to use terrorism to achieve his goal, and writes that 'factories should be destroyed, technical books burned, etc. '[36] That is a far-reaching 'etc.' In order to render it impossible for any part of society to return to industrialization, his revolutionaries would presumably need to burn all advanced libraries, destroy all computers that contain Wikipedia or scientific articles, and either imprison, brainwash, or execute everyone with an advanced scientific education. Recall that the revolutionaries should have no 'scruples' and proceed 'no matter what.'[37] Moreover, for the anti-tech revolution to lead to a successful outcome, it would seemingly need to be part of a coordinated shutdown of industrial civilization in every country on Earth. Unless the shutdown is well coordinated, then by Kaczynski's own admission, some countries would be likely to continue to use advanced technologies and would gain a comparative advantage by so doing. Interestingly, Kaczynski recommends that his 
own revolutionaries make use of technology to gain the upper hand. He suggests, however, that they will nevertheless phase out technology and give up their power. ${ }^{[38]}$

Does Kaczynski believe that this will work according to plan? Although it is of course possible that he does, such a belief sits uncomfortably both with his skepticism about our ability to predict the future and his more general outlook on society, which is decisively cynical and pessimistic. Whatever Kaczynski's shortcomings are, he is not a naïve do-gooder. If he doesn't believe that his proposed solution is likely to be successful, however, then why would he propose it? My hypothesis is that, yet again, Kaczynski's conclusions are not driven by his empirical premises, but by the theoretical assumptions that he brings to the discussion. One of these is the already stated assumption that unless humanity returns to pre-industrial ways of living, we face either eradication or Brave New World. This assumption admittedly concerns an empirical matter, but it is one for which Kaczynski does not provide any support. Another assumption, which is evaluative, is that both of these outcomes are so bad that they are worth avoiding at any cost. Recall that life in preindustrial society involves very little that, on Kaczynski's view, is bad in an ethically relevant way (he thinks that one can always remain stoic), and that life in industrial society includes very little that is good in an ethically relevant way (he does not count the benefits of industrialization). Therefore, given Kaczynski's ethical outlook, we have nothing to lose in the fight against industrial society. Indeed, fighting industrial society becomes structurally similar to escaping a concentration camp: Although the escape might not be successful, and although it might involve a lot of suffering, we should nevertheless try, since all that is good exists on the outside. On this interpretation, Kaczynski does not have to believe that the anti-tech revolutionaries will be successful. Rather, his justification can be driven-as I believe it is - by the assumption that any bombed-out world, and any amount of suffering that is necessary to get there, is ethically superior to any future technological civilization. The devil, we might say, is in the ethics.

\section{CONCLUSION}

In this paper I have sought to give a concise presentation of Ted Kaczynski's views as stated in 'Industrial Society and its Future' (1995) and Anti-Tech Revolution (2016). I have further argued that although he raises a number of legitimate worries, his assessment as a whole is unconvincing. It is unconvincing, first and foremost, because it rests on evaluative standards according to which technology is almost automatically taken to be bad and non-technology is almost automatically taken to be good (or at least not bad). These standards, on which both his estimation of the state of the world and his practical recommendations rest, are at once highly revisionist and unsupported by argument.

My challenge to those who find Kaczynski's ideas appealing is that they should either defend his revisionist standards of evaluation (which would be a philosophical endeavor) or, alternatively, show that that the same conclusions can be reached even if we apply less revisionist standards. Until or unless such a case has been made, Kaczynski's distinctive normative conclusion-that we should seek to end industrialization, through terrorism if necessary-must be rejected. If we are genuinely concerned about the negative effects of technological development, and our aim is to secure a good future for humanity, recommendations along the lines of Bostrom and Savulescu seem far more promising.

In addition to being an interesting case in its own right, Kaczynski's writings and actions can serve to highlight a more general point, namely that intelligent people can have glaring philosophical blind spots, and that philosophical errors can have grave practical consequences, including terrorism. Since the continuing development of bioweapons, nanoweapons, and Al weapons increases the potential threat (including existential threat ${ }^{[39)}$ ) posed by terrorists, we urgently need to find new ways to discourage people from committing acts of terrorism. I believe academic philosophers can contribute to discourage terrorism by scrutinizing the ideas that motivate terrorists. Philosophers should work to reconstruct the positions of dangerous ideologues and religious extremists, identify their supporting arguments, distinguish their empirical premises from their normative premises, and use the tools philosophical argumentation to explain where, precisely, they err and how their positions can be amended in ways that avoid error. 
Although philosophers can only play a modest role in fighting terrorism, it is striking that, today, the most obvious line of response to one's adversaries - to listen carefully, to show that one has understood their position, and to explain why one believes they are mistaken - is hardly even attempted as a means to discourage terrorists. To the extent that ideological violence is indeed ideological, however, I believe that in many cases, philosophical scrutiny can discourage terrorism more effectively than condemnation and threats of retaliation. This paper is intended as one example of how one might engage philosophically with ideas that have motivated deadly violence in the past, and that might do so again - possibly with even more serious consequences - if the sloppy philosophical reasoning on which they are based is never pointed out.

ш T. Kaczynski. Industrial Society and its Future. Available at: theanarchistlibrary.org [Accessed 30 April, 2018.] The manifesto has numbered paragraphs. Since these remain constant across all editions, while page numbers vary, I have chosen to refer to paragraph numbers.

[2] T. Kaczynski. 2016. Anti-Tech Revolution: Why and How. Scottsdale, AZ: Fitch \& Madison Publishers. Available at: we.riseup.net [Accessed 30 April, 2018]

${ }^{[3]}$ Kaczynski also contributed to the book Technological Slavery, published in 2008. In the foreword, however, Kaczynski expresses dissatisfaction about the book and claims that he has had limited control over its making. Partly for this reason, and partly because I cannot find any ideas in Technological Slavery that aren't discussed in more detail in AntiTech Revolution, I ignore Technological Slavery in this paper. See T. Kaczynski. 2008. Technological Slavery. Port Townsend, WA: Feral House.

[4] Sodroski, A., Clemente J. \& Gittelson T. (2017). Manhunt: Unabomber. Discovery Channel.

[5] The book is Technological Slavery (see footnote 3). See D. Skrbina. A Revolutionary for Our Time. Available at theanarchistlibrary.org (accessed 30 April, 2018.) Skrbina also discusses Kaczynski's ideas in D. Skrbina. 2014. The Metaphysics of Technology. New York: Routledge: 168-72.

[6] J. Q. Wilson. 1998. In Search of Madness. New York Times. 15 Jan. Available

at: http://www.nytimes.com/1998/01/15/opinion/in-search-of-madness.html [Accessed 4 Nov, 2018). Kaczynski was a student at Harvard while Wilson taught there. Kaczynski also mentions Wilson in his manifesto: 'Eminent social scientists (e.g. James Q. Wilson) have stressed the importance of 'socializing' people more effectively.' (§139) Given the context, this should be read as a disapproving remark.

\ Kaczynski. Industrial Society and Its Future: §46-47.

[8] Ibid: $§ 68$.

[9] Ibid: §65. Sigmund Freud raised very similar worries in Civilization and Its Discontents. Notice the structural similarities between Freud's and Kaczynski' titles. See Freud, S. (2002). Civilization and its discontents. London: Penguin.

$[101$ Ibid: §89. In order to defend the view that scientific research is largely a surrogate activity, Kaczynski writes that '[s]ome scientific work has no conceivable relation to the welfare of the human race most of archaeology or comparative linguistics for example.' (§88) This is an interesting choice of examples. Presumably, archaeology is important to understand the societies that Kaczynski wants to re-establish. Comparative linguistics, moreover, helped get Kaczynski convicted: Linguistic idiosyncrasies in his writings were crucial to connecting Kaczynski to the manifesto.

[11] Ibid: $\$ 127$.

[12] Ibid: $\$ 128$.

[13] Ibid: $\$ 174$.

[14] Ibid: §184, §208.

[15] Ibid: §166-68.

[16] Kaczynski. Anti-Tech Revolution: 17, 31.

[17] Ibid: 167.

[18] Ibid: 148.

[19] Ibid: 135.

[20] Ibid: 143.

[21] lbid: 149-153.

[22] J. Norberg. Progress. Oneworld: London 2016: 3-4; M. Roser. 'Life Expectancy.' OurWorldlnData.org. Available at: https://ourworldindata.org/life-expectancy/ [Accessed 30 April, 2017] 
${ }^{[23]}$ For a recent case for the positive impact of science and technology, see S. Pinker. 2018. Enlightenment Now. New York: Viking: Part II.

${ }^{[24]}$ Kaczynski. Industrial Society and Its Future: §69. Kaczynski rejects Anarcho-Primitivist views according to which 'primitive' life was idyllic. See T. Kaczynski. The Truth About Primitive Life: A Critique of Anarchoprimitivism. Available at: https://theanarchistlibrary.org/library/ted-kaczynski-the-truth-about-primitive-life-a-critique-ofanarchoprimitivism.pdf [Accessed April 30, 2018).

[25] Kaczynski. Industrial Society and Its Future: 69.

[26] Ibid: $§ 73$.

[27] lbid: $\$ 76$.

[28] B. Joy. 2000. Why the Future Doesn't Need Us. Wired. 4 Jan. Available at: www.wired.com Joy acknowledges that he was influenced by Kaczynski: 'Kaczynski's actions were murderous and, in my view, criminally insane. He is clearly a Luddite, but simply saying this does not dismiss his argument; as difficult as it is for me to acknowledge, I saw some merit in the reasoning [...]'

[29] N. Bostrom. 2014. Superintelligence. Oxford: Oxford University Press.

$[301$ I. Persson \& J. Savulescu. 2012. Unfit for the future. Oxford: Oxford University Press.

${ }^{[311}$ See, in particular, N. Bostrom. Letter from Utopia. Stud Ethics Law Technol, 2008: 1: 1-7; J. Savulescu, A. Sandberg \& G. Kahane. Well-Being and Enhancement. In J. Savulescu, G. Kahane \& R. Meulen, ed. 2011. Enhancing Human Capacities. Oxford: Blackwell Publishing: 3-19.

[32] Kaczynski. Anti-Tech Revolution: 17.

${ }^{[33]}$ See N. Bostrom, A. Dafoe \& Carrick Flynn. Policy Desiderata in the Development of Superintelligent Al. Working paper. Available at: https://nickbostrom.com/papers/aipolicy.pdf (Accessed 30 April, 2017)

[34] Persson \& Savulescu. Unfit for the Future: Chap. 10.

[35] Kaczynski. Industrial Society and Its Future: $\$ 176$.

[36] Ibid: $\$ 166$.

[37] Ibid: $\$ 149-153$.

[38] Kaczynski. Anti-Tech Revolution: 175.

${ }^{[39]}$ For a recent paper on this threat, which briefly discusses Ted Kaczynski, see P. Torres. Moral bioenhancement and agential risks: Good and bad outcomes. Bioethics 2017; 31: 691-696. 